\title{
ETHzürich
}

ETH Library

\section{Mass and kinetic energy distribution of the species generated by laser ablation of La0.6Ca0.4MnO3}

Journal Article

Author(s):

Canulescu, S.; Lippert, Thomas; Wokaun, Alexander

Publication date:

2008

Permanent link:

https://doi.org/10.3929/ethz-b-000012723

Rights / license:

In Copyright - Non-Commercial Use Permitted

Originally published in:

Applied Physics A 93(3), https://doi.org/10.1007/s00339-008-4710-0 


\title{
Mass and kinetic energy distribution of the species generated by laser ablation of $\mathrm{La}_{0.6} \mathrm{Ca}_{0.4} \mathrm{MnO}_{3}$
}

\author{
S. Canulescu • T. Lippert • A. Wokaun
}

Received: 12 October 2007 / Accepted: 4 March 2008 / Published online: 13 June 2008

(C) Springer-Verlag 2008

\begin{abstract}
The mass distributions of the species generated by laser ablation from a $\mathrm{La}_{0.6} \mathrm{Ca}_{0.4} \mathrm{MnO}_{3}$ target using laser irradiation wavelengths of $193 \mathrm{~nm}, 266 \mathrm{~nm}$ and $308 \mathrm{~nm}$ have been investigated with and without a synchronized gas pulse of $\mathrm{N}_{2} \mathrm{O}$. The kinetic energies of the species are measured using an electrostatic deflection energy analyzer, while the mass distributions of the species were analyzed with a quadrupole mass filter.

In vacuum (pressure $10^{-7} \mathrm{mbar}$ ), the ablation plume consists of metal atoms and ions such as $\mathrm{La}, \mathrm{Ca}, \mathrm{Mn}, \mathrm{O}, \mathrm{LaO}$, as well as multiatomic species, e.g. $\mathrm{LaMnO}^{+}$. The $\mathrm{LaO}^{+}$diatomic species are by far the most intense diatomic species in the plume, while $\mathrm{CaO}$ and $\mathrm{MnO}$ are only detected in small amounts.

The interaction of a reactive $\mathrm{N}_{2} \mathrm{O}$ gas pulse with the $\mathrm{ab}$ lation plume leads to an increase in plume reactivity, which is desired when thin manganite films are grown, in order to incorporate the necessary amount of oxygen into the film. The $\mathrm{N}_{2} \mathrm{O}$ gas pulse appears to have a significant influence on the oxidation of the Mn species in the plume, and on the creation of negative ions, such as $\mathrm{LaO}^{-}, \mathrm{O}^{-}$and $\mathrm{O}_{2}^{-}$.
\end{abstract}

PACS 42.62.-b · 42.70.Hj · 52.27.Cm · 52.38.-r ·

52.40.-w $\cdot 75.47 . \mathrm{Lx} \cdot 82.80 . \mathrm{Ms}$

\section{Introduction}

The manganite materials have attracted scientific as well as technological interest due to their colossal magnetoresistance properties (CMR). The CMR effect is mainly related

S. Canulescu $\cdot$ T. Lippert $(\varangle) \cdot$ A. Wokaun

Paul Scherrer Institut, 5232 Villigen, Switzerland

e-mail: thomas.lippert@psi.ch to the mobility of the $e_{g}$ carriers in the $\mathrm{Mn}^{3+}-\mathrm{O}^{2-}-\mathrm{Mn}^{4+}$ network, which is facilitated through the intermediate of the oxygen ions in the perovskite structure [1]. The oxygen content plays therefore an important role in the transport properties of manganites in the bulk and thin films [2].

Laser ablation is a suitable technique for the deposition of manganite films with a complex stoichiometry [3]. One approach to improve the oxygen content in the films was the development of pulsed reactive crossed beam laser ablation (PRCLA), where a synchronized reactive gas pulse interacts with the plasma plume close to its origin [4]. This leads to a high probability of reactive scattering of the plasma with the oxidizing source [5]. Previous plasma studies on $\mathrm{Mn}_{2} \mathrm{O}_{3}$ and $\mathrm{La}_{0.67} \mathrm{Sr}_{0.33} \mathrm{MnO}_{3}$ targets using emission spectroscopy have shown that a larger amount of Mn oxides is present when $\mathrm{N}_{2} \mathrm{O}$ is supplied as background gas compared to $\mathrm{O}_{2}$ [6].

Detailed studies of the plume composition induced by laser ablation of manganites will help to understand the role of oxygen and oxide species in the laser ablation process and film growth. We report on mass spectrometry analysis of the plume induced by laser ablation of a $\mathrm{La}_{0.6} \mathrm{Ca}_{0.4} \mathrm{MnO}_{3}$ target as a function of the irradiation wavelength in vacuum and in the presence of a synchronized reactive $\mathrm{N}_{2} \mathrm{O}$ gas pulse. The kinetic energies of the positive/negative ions or neutrals generated during the ablation process were directly measured using a kinetic energy analyzer.

\section{Experimental}

The ablation experiments were performed in a vacuum chamber with a residual pressure of $\approx 5 \times 10^{-6} \mathrm{~Pa}$. Two different oxidizing sources were used, e.g. $\mathrm{O}_{2}$ as background gas $\left(p=8 \times 10^{-2} \mathrm{~Pa}\right)$ and $\mathrm{N}_{2} \mathrm{O}$ for the gas pulse 
( $p=200 \mathrm{kPa}$, duration $400 \mu \mathrm{s}$ ), which leads to an overall pressure in the chamber of $0.1 \mathrm{~Pa}$. These conditions are typical for the deposition of $\mathrm{La}_{0.7} \mathrm{Ca}_{0.3} \mathrm{MnO}_{3}$ thin films. Different laser wavelengths were employed for the ablation experiments, e.g. $193 \mathrm{~nm}$ (ArF excimer laser), $308 \mathrm{~nm}$ (XeCl excimer laser) and $266 \mathrm{~nm}$ (Nd: YAG laser). The laser beam was focused on a cylindrical target at laser fluence of $0.5 \mathrm{Jcm}^{-2}$. The distance between the point of ablation on the target and the synchronized gas pulse was $\sim 1 \mathrm{~cm}$.

A quadrupole mass spectrometer (EQP 500) with a mass ranging from 1 to $500 \mathrm{amu}$ was used to monitor the plume species. The kinetic energy of the species was measured using an electrostatic energy analyzer whose settings were tuned to allow for a kinetic energy (KE) analysis of the particles with the selected mass to charge ratio. The differential pumping system of the EQP maintains a pressure in the analysis chamber of $<5 \times 10^{-5} \mathrm{~Pa}$, while the pressure in the ablation chamber was set to $0.1 \mathrm{~Pa}$. The neutral species entering into the cage section of the mass spectrometer are ionized using a $70 \mathrm{eV}$ dual filament electron impact ionization source, and the positive species are detected with the ionizer switched off. During the neutral detection, the EQP extractor was set to a voltage of $50 \mathrm{~V}$, in order to repel all ions with $\mathrm{KE} \leq 50 \mathrm{eV}$. The axis of the mass spectrometer was placed at the intersection between the plasma plume and the gas pulse, and the nozzle of the mass spectrometer was located at $10 \mathrm{~cm}$ from the target. An event reference signal was used to trigger the mass spectrometer (through the intermediate of the mass spectrometer interface unit: MSIU) with the laser. The spectra were acquired at a laser frequency of $10 \mathrm{~Hz}$.

\section{Results and discussion}

\subsection{Studies of the plume composition in vacuum}

The mass distributions of the ionic and neutral species generated by laser ablation of the $\mathrm{La}-\mathrm{Ca}-\mathrm{Mn}-\mathrm{O}$ target at $266 \mathrm{~nm}$ using a laser fluence of $0.5 \mathrm{Jcm}^{-2}$ are shown in Fig. 1. The ablation plume of the manganite target consists of ionic and neutral atoms, such as $\mathrm{La}, \mathrm{Ca}, \mathrm{Mn}, \mathrm{LaO}$, as well as a polyatomic species ( $\mathrm{LaMnO})$. The $\mathrm{LaMnO}$ species is most probably formed during secondary interactions between the plume species in the gas phase.

Comparing the relative intensity of the ablation yield (see Fig. 1), it can be observed that the $\mathrm{LaO}$ species are the second most abundant species after $\mathrm{La}$, while neither $\mathrm{MnO}$ nor $\mathrm{CaO}$ could be detected. This raises the question of the origin of the $\mathrm{LaO}$ diatomic species in the ablation plume. One possible source may be a direct ejection of the diatomic species from the target, while the second one is the formation of the diatomic species in the gas phase. The first mechanism could explain why only $\mathrm{LaO}$ is detected for irradiation at $266 \mathrm{~nm}$.
Table 1 Bond dissociation energies of the diatomic species and exothermicity values [11]

\begin{tabular}{lllll}
\hline & $\mathrm{LaO}$ & $\mathrm{CaO}$ & $\mathrm{MnO}$ & $\mathrm{N}_{2} \mathrm{O}$ \\
\hline $\begin{array}{l}\text { Dissociation } \\
\text { energy (eV) }\end{array}$ & $8.2( \pm 0.17)$ & $4.12( \pm 0.17)$ & $4.13( \pm 0.43)$ & 2.51 \\
\begin{tabular}{l} 
Exothermicity \\
\hline
\end{tabular} & 5.4 & 1.59 & $1.61^{\mathrm{a}}$ & 0 \\
\hline
\end{tabular}

${ }^{\mathrm{a}}$ The reaction of the $\mathrm{Mn}$ in $\mathrm{O}_{2}$ endothermic $(-1 \mathrm{eV})$

Table 2 The ion to neutral ratios generated at different irradiation wavelengths and at a laser fluence of $0.5 \mathrm{Jcm}^{-2}$

\begin{tabular}{llll}
\hline Species & \multicolumn{3}{l}{ Ions to neutral ratio $\mathrm{M}^{+} / \mathrm{M}$} \\
\cline { 2 - 4 } & $193 \mathrm{~nm}(6.7 \mathrm{eV})$ & $266 \mathrm{~nm}(4.7 \mathrm{eV})$ & $308 \mathrm{~nm}(4.02 \mathrm{eV})$ \\
\hline $\mathrm{La}^{+} / \mathrm{La}$ & 6.9 & 0.8 & 0.9 \\
$\mathrm{Ca}^{+} / \mathrm{Ca}$ & 14.9 & 10.4 & 8.7 \\
$\mathrm{Mn}^{+} / \mathrm{Mn}$ & 0.5 & 0.6 & 1.8 \\
$\mathrm{LaO}^{+} / \mathrm{LaO}$ & 3.5 & 2.7 & 1.8 \\
\hline
\end{tabular}

$\mathrm{LaO}$ has the highest dissociation energy of the three oxides (summarized in Table 1), while the photon energy at $266 \mathrm{~nm}$ may be sufficient to decompose $\mathrm{CaO}$ and $\mathrm{MnO}$, but not $\mathrm{LaO}$. In order to investigate the photodecomposition of the metal oxides species as a function of photon energy, different wavelengths, e.g. $6.7 \mathrm{eV}(193 \mathrm{~nm}), 4.7 \mathrm{eV}(266 \mathrm{mn})$ and $4.02 \mathrm{eV}(308 \mathrm{~nm})$ have been tested. The bond dissociation energies of the diatomic species are summarized in Table 1. At an irradiation wavelength of $308 \mathrm{~nm}$ laser irradiation, the photons energy $(4.02 \mathrm{eV})$ is smaller than the dissociation energy of $\mathrm{CaO}$ and $\mathrm{MnO}$, while for $266 \mathrm{~nm}$ and $193 \mathrm{~nm}$ the decomposition would be possible. However, decreasing the photon energy, no $\mathrm{MnO}$ and $\mathrm{CaO}$ species are observed. This suggests that the absence of $\mathrm{MnO}$ and $\mathrm{CaO}$ diatomic species in the plume is not related to the photon energy. The $\mathrm{LaO}$ species observed in the mass spectra may be related to the high bond stability of the $\mathrm{LaO}$ molecules and/or that the $\mathrm{LaO}$ oxides are preferentially formed (compared to $\mathrm{MnO}$ and $\mathrm{CaO}$ ) in the gas phase. One possible reason is the high exothermicity of the formation of $\mathrm{LaO}$ compared to $\mathrm{MnO}$ and $\mathrm{CaO}$, which would explain the preferential formation.

Furthermore, with increasing photon energy, an increase of the ion yield is observed. In Table 2 a comparison between ion to neutral ratios at different wavelengths is summarized. The first ionization potential of the target components $\mathrm{La}, \mathrm{Ca}, \mathrm{Mn}$ are at $5.58 \mathrm{eV}, 6.13 \mathrm{eV}$ and $7.435 \mathrm{eV}$, respectively. The ArF laser photons $(6.7 \mathrm{eV})$ provide therefore enough energy to ionize most of the plume species with a single photon, resulting in a higher yield of ions compared to $266 \mathrm{~nm}$ and $308 \mathrm{~nm}$ irradiation (Table 2), with the exception of $\mathrm{Mn}$, where the $\mathrm{M}^{+} / \mathrm{M}$ ratio increases with the irradiation wavelength. The $\mathrm{M}^{+} / \mathrm{M}$ ratio is smaller for the $\mathrm{Mn}$ species compared to the other metal species, which is con- 


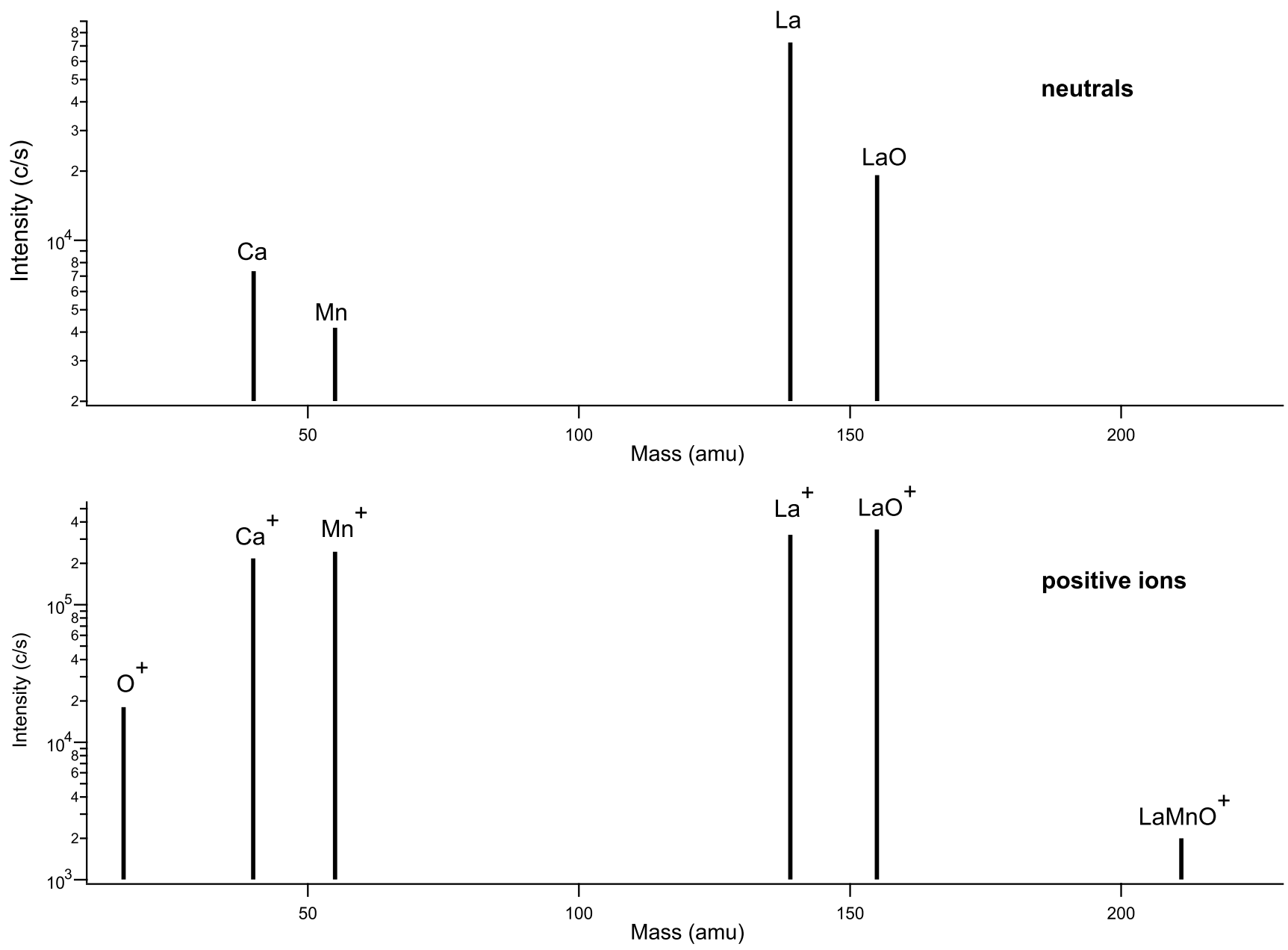

Fig. 1 Mass spectra of the neutrals and ions generated by laser ablation of the $\mathrm{La}_{0.6} \mathrm{Ca}_{0.4} \mathrm{MnO}_{3}$ target in vacuum using an irradiation wavelength of $266 \mathrm{~nm}$ and a laser fluence of $0.5 \mathrm{Jcm}^{-2}$

sistent with the highest ionization potential of Mn, but this suggests also that the ionization is possible by multiphoton ionization. For all irradiation wavelengths the intensities reveal the same trend $\left(\mathrm{Ca}^{+}>\mathrm{LaO}^{+}>\mathrm{Ca}^{+}>\mathrm{Mn}^{+}\right)$, while no clear trend is observed for the neutrals. It is noteworthy to mention that for $193 \mathrm{~nm}$ irradiation, the diatomic $\mathrm{LaO}$ reveals the highest intensity.

\subsection{Studies on the plume interaction with a reactive $\mathrm{N}_{2} \mathrm{O}$ gas pulse}

\subsubsection{Mass distribution of the plume species}

Figure 2 shows the mass spectra of the ionic and neutral species produced by laser ablation of the LCMO target in the presence of the reactive $\mathrm{N}_{2} \mathrm{O}$ gas pulse. No signals from the $\mathrm{N}_{2}$ species were detected, suggesting that this volatile species is removed by pumping. There have also been no detectable traces of nitrogen in the grown film. Reactive collisions between the plasma plume and the supersonic gas pulse lead to the formation of various additional neutral species (compared with the experiments in vacuum), such as $\mathrm{O}, \mathrm{MnO}, \mathrm{CaO}$, and $\mathrm{O}_{2}$. The mass distribution of the ionic species consists of atomic ions, such as $\mathrm{La}, \mathrm{Ca}, \mathrm{Mn}, \mathrm{O}$, and diatomic species, such as $\mathrm{LaO}, \mathrm{O}_{2}, \mathrm{CaO}, \mathrm{MnO}$, as well as multiatomic ions $\left(\mathrm{MnO}_{2}\right)$. One important aspect is the presence of various negative ions, such as $\mathrm{O}^{-}, \mathrm{O}^{2-}$ and $\mathrm{LaO}^{-}$.

The generation of the reactive atomic oxygen through the collisional dissociation of the $\mathrm{N}_{2} \mathrm{O}$ molecules $\left(\mathrm{N}_{2} \mathrm{O} \rightarrow\right.$ $\mathrm{N}_{2}+\mathrm{O}$ ) requires an energy of $2.51 \mathrm{eV}$, which is twice lower than from the dissociation of $\mathrm{O}_{2}$ [6]. $\mathrm{N}_{2} \mathrm{O}$ is therefore more efficient in producing atomic oxygen species than $\mathrm{O}_{2}$. There are other subsequent processes in the plume responsible for the formation of negative ions [7], positive ions, and diatomic species, which are important for the film formation. The translational energy of the positive/negative $\mathrm{O}$ ions measured by positive/negative bias tuning of the electrostatic energy analyzer lenses is shown in Fig. 3. In vacuum, the $\mathrm{O}^{+}$species exhibits a high translational energy, with a main distribution of $\sim 16 \mathrm{eV}$, as is shown in Fig. 3. The energy 

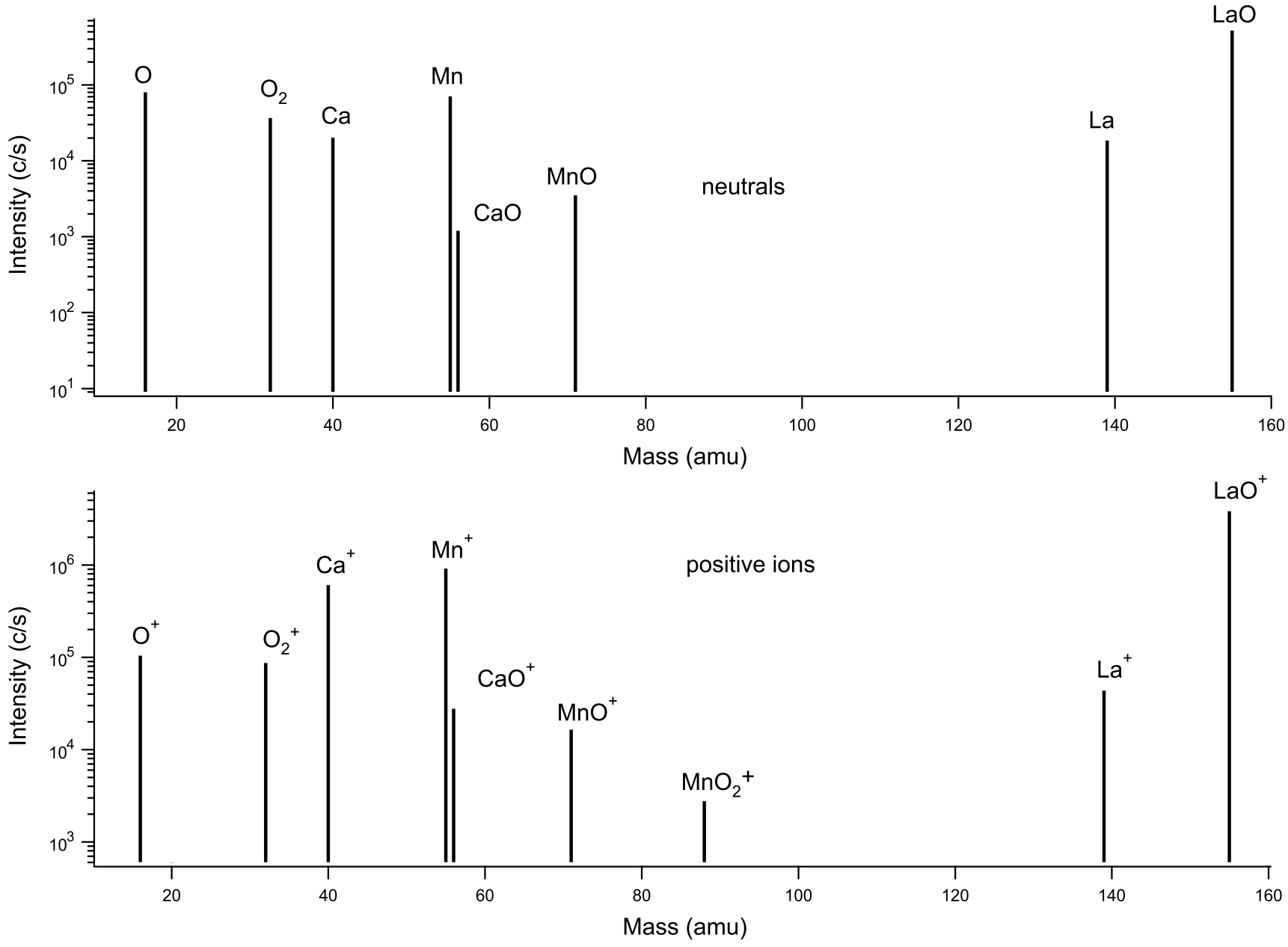

Fig. 2 The mass scan of the ionic and neutral species emitted by $266 \mathrm{~nm}$ laser irradiation in the presence of a reactive $\mathrm{N}_{2} \mathrm{O}$ gas pulse at a laser fluence of $0.5 \mathrm{Jcm}^{-2}$

distribution of the $\mathrm{O}^{+}$species is very broad, while in the presence of the gas pulse (pulse on in Fig. 3, top), the main energy distribution narrows at $\sim 3.5 \mathrm{eV}$, which is similar to the kinetic energies of the other species (Table 2). It has been suggested that $\mathrm{O}^{+}$is produced by direct ejection from the target in vacuum [8], but the origin of the large kinetic energy of the $\mathrm{O}^{+}$species of up to $20 \mathrm{eV}$ is not completely understood at the moment.

The negative $\mathrm{O}^{-}$ions are dominant among the plume species when the $\mathrm{N}_{2} \mathrm{O}$ gas pulse is applied. The main kinetic energy distribution of the negative ions is $\sim 1.8 \mathrm{eV}$. The large amount of $\mathrm{O}^{-}$ions suggests that it may be necessary to consider the $\mathrm{O}^{-}$negative ions when PRCLA is applied, i.e. they may be related to the increased oxygen content in films for PRCLA grown films compared with PLD.

\subsubsection{Formation of diatomic species}

When the $\mathrm{La}, \mathrm{Ca}, \mathrm{Mn}$ species in the plume interact with the $\mathrm{N}_{2} \mathrm{O}$ gas pulse, metal oxides species are formed with the reactive oxygen species $\left(\mathrm{O}, \mathrm{O}^{+}, \mathrm{O}^{-}, \mathrm{O}_{2}\right)$, which are created during collisions of the plume species with $\mathrm{N}_{2} \mathrm{O}$ and the background gas molecules. Formation of the excited diatomic species in the gas phase has previously been observed using the optical emission spectroscopy technique [9], although there were almost no $\mathrm{MnO}$ ions detected in the presence of a static oxygen background up to $0.1 \mathrm{~Pa}$. The creation of the oxides is therefore mainly related to the $\mathrm{N}_{2} \mathrm{O}$ gas pulse.

The formation of the $\mathrm{MnO}$ and $\mathrm{CaO}$ species is almost equally favorable due to their comparable dissociation energy and exothermicity values. The detection of $\mathrm{LaMnO}^{+}$ is only possible when the plume is directed exactly to the entrance nozzle of the mass spectrometer, as in the case of analysis in vacuum (see Fig. 4b). For the experiments with the gas pulse, the axis of the mass spectrometer is placed in between the ablation plume and gas pulse (see Fig. 4a), i.e. at the preferred position of the substrate in PRCLA. The very low intensity of $\mathrm{LaMnO}^{+}$detected suggests that the heavy species have a narrow angular distribution. 

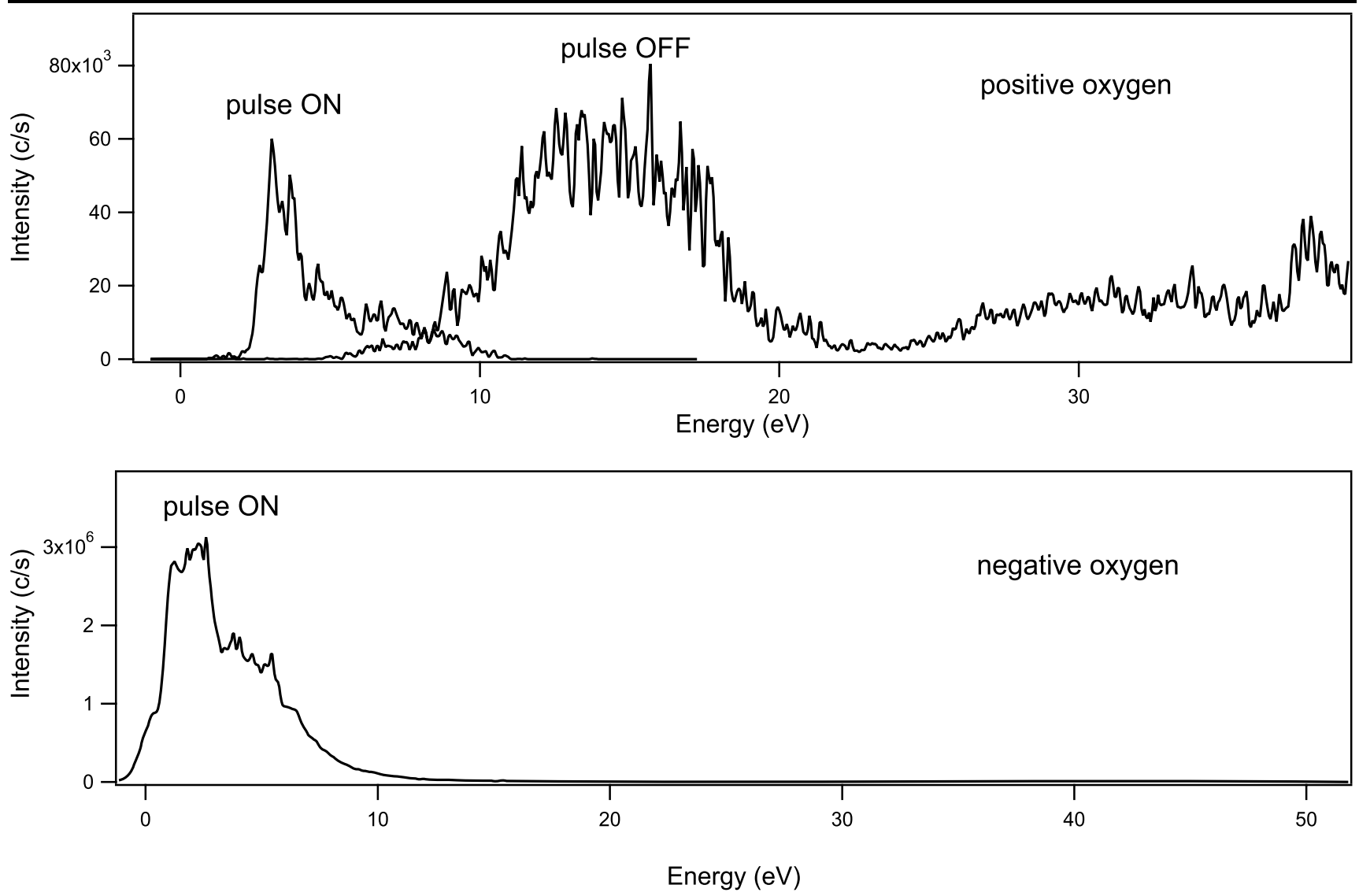

Fig. 3 Energy spectra of $\mathrm{O}^{+}$and $\mathrm{O}^{-}$in vacuum and in the presence of gas pulse $\mathrm{N}_{2} \mathrm{O}$, induced by 266 nm laser irradiation at a laser fluence of $0.5 \mathrm{Jcm}^{-2}$
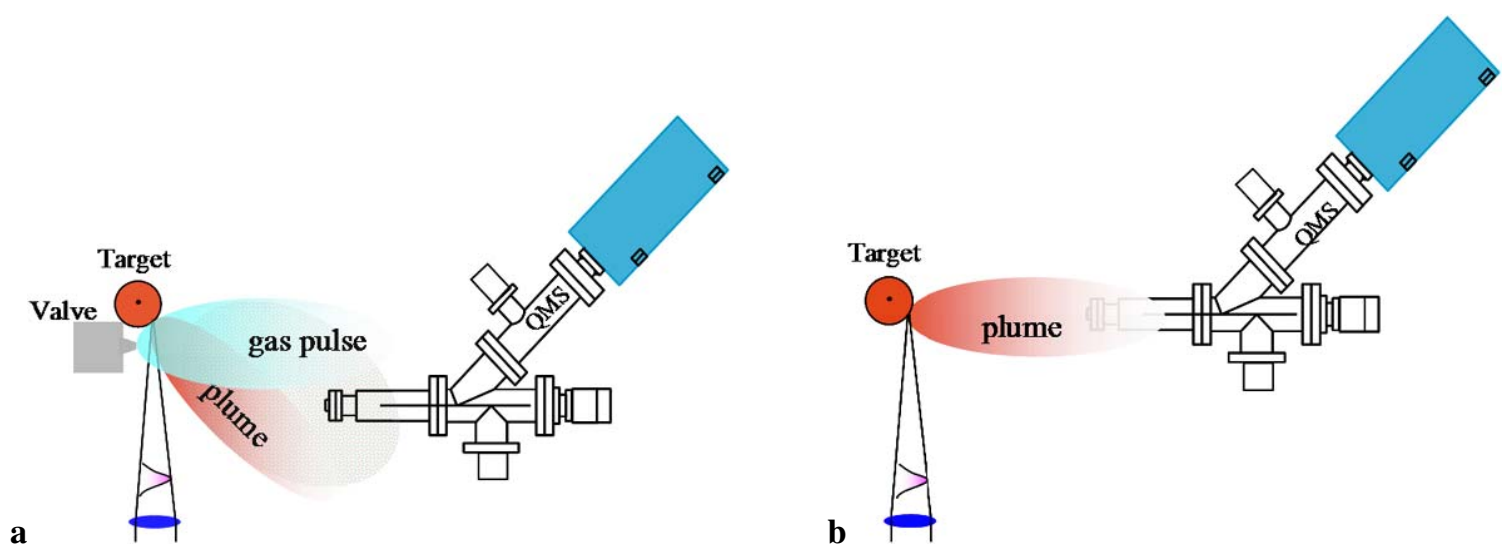

Fig. 4 Off-axis configuration of the mass spectrometer, allowing for detection of the species generated by collisions with gas pulse particles (a) and on-axis configuration of the mass spectrometer, allowing for detection of the particles along the plume expansion (b)

\subsubsection{Positive diatomic ions}

The positive $\mathrm{CaO}^{+}$and $\mathrm{MnO}^{+}$species are most probably formed during interactions between plume species and the gas pulse (as these species are not detected in vacuum), e.g. by reactions of the metal species with the oxygen species formed during dissociation of $\mathrm{N}_{2} \mathrm{O}$ molecules
$\left(\mathrm{M}^{+}+\mathrm{O}_{2} \rightarrow \mathrm{MO}^{+}+\mathrm{O}\right)[8]$ and/or from collisions with the oxygen background, which is much less likely as discussed above. The $\mathrm{LaO}^{+}$yield for example increases by more than one order of magnitude compared with the experiments in vacuum. Figure 5 shows the kinetic energies of positive ions formed during interactions with the gas pulse. The measured kinetic energy distribution of the positive ions reveals a main 

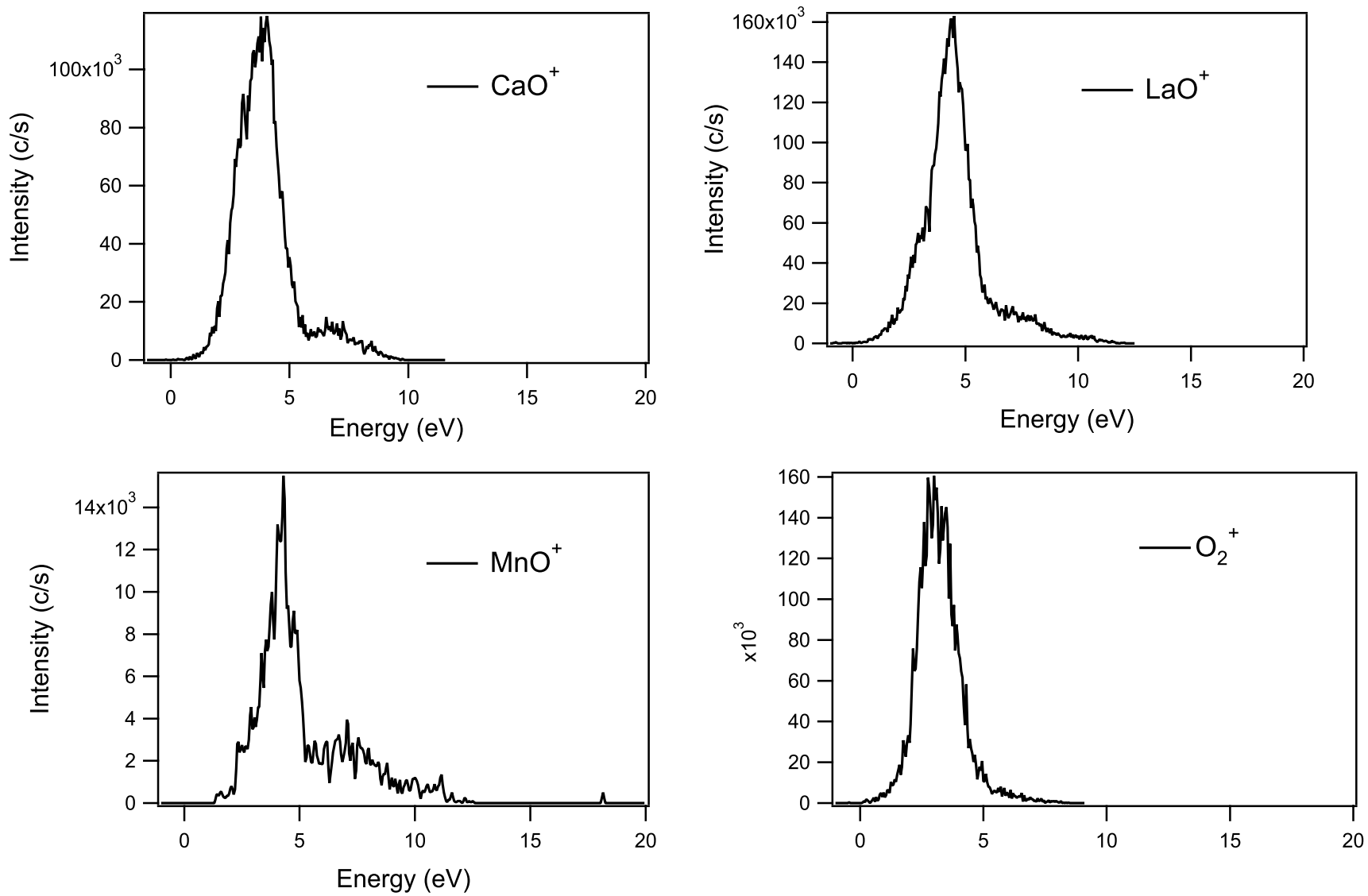

Fig. 5 Measured kinetic-energy distributions of the positively charged species for $266 \mathrm{~nm}$ irradiation and in the presence of $\mathrm{N}_{2} \mathrm{O}$ gas pulse

Table 3 The maximum kinetic energy values of the plume species for irradiation at $266 \mathrm{~nm}, \phi=0.5 \mathrm{Jcm}^{-2}$ in vacuum and in the presence of the $\mathrm{N}_{2} \mathrm{O}$ gas pulse

\begin{tabular}{|c|c|c|c|c|c|}
\hline \multirow[b]{2}{*}{ Species } & \multicolumn{2}{|c|}{ Vacuum $\left(<10^{-7} \mathrm{~Pa}\right)$} & \multicolumn{3}{|c|}{ Gas pulse $(0.1 \mathrm{~Pa})$} \\
\hline & $\overline{\mathrm{M}^{+}}$ & $\mathrm{M}$ & $\overline{\mathrm{M}^{+}}$ & $\mathrm{M}^{-}$ & $\mathrm{M}$ \\
\hline $\mathrm{La}$ & $5.2 \mathrm{eV}$ & $2.3 \mathrm{eV}$ & $4.1 \mathrm{eV}$ & $-1-$ & $2.3 \mathrm{eV}$ \\
\hline $\mathrm{Ca}$ & $4.2 \mathrm{eV}$ & $2 \mathrm{eV}$ & $3.3 \mathrm{eV}$ & $-1-$ & $2 \mathrm{eV}$ \\
\hline $\mathrm{Mn}$ & $5 \mathrm{eV}$ & $2.6 \mathrm{eV}$ & $3.5 \mathrm{eV}$ & $-1-$ & $2.1 \mathrm{eV}$ \\
\hline $\mathrm{O}$ & $16 \mathrm{eV}$ & $-/-$ & $3.4 \mathrm{eV}$ & $1.7 \mathrm{eV}$ & $-/-$ \\
\hline $\mathrm{O}_{2}$ & $-/-$ & $1 \mathrm{eV}$ & $3 \mathrm{eV}$ & $1 \mathrm{eV}$ & $-1-$ \\
\hline $\mathrm{LaO}$ & $5.1 \mathrm{eV}$ & $3 \mathrm{eV}$ & $4.3 \mathrm{eV}$ & $1.8 \mathrm{eV}$ & $2 \mathrm{eV}$ \\
\hline $\mathrm{CaO}$ & $-1-$ & $-1-$ & $3.7 \mathrm{eV}$ & $1 \mathrm{eV}$ & $1.6 \mathrm{eV}$ \\
\hline $\mathrm{MnO}$ & $-1-$ & $-1-$ & $4.2 \mathrm{eV}$ & $0.9 \mathrm{eV}$ & $1.7 \mathrm{eV}$ \\
\hline
\end{tabular}

distribution peak in the low energy region $(2-4 \mathrm{eV})$ as well as a smaller contribution at higher energy, i.e. $\sim 6-8 \mathrm{eV}$. The main energy values derived from the energy distributions are summarized in Table 3.

3.2.3.1 Negative diatomic ions The presence of negatively charged ions emitted by laser ablation, e.g. from sodium trisilicate glass using the TOF mass spectrometry technique has been reported previously [10]. To our knowledge, no reports have been published on negative ion emission during irradiation of a manganite target.
In general, the intensity of the negative species is lower than for the positive species, with the exception of the negative $\mathrm{O}^{-}$and $\mathrm{O}^{2-}$ ions, which are formed in high yield during interaction of the plume with the $\mathrm{N}_{2} \mathrm{O}$ gas pulse. The measured kinetic energy spectra of all detected negative ions are shown in Fig. 6, revealing a main distribution ranging between $1 \mathrm{eV}$ and $2 \mathrm{eV}$. It is noteworthy that the intensity of the $\mathrm{O}^{2-}$ species is three orders of magnitude higher than for $\mathrm{CaO}^{-}$. In Table 3 the main energy distributions of the negative ions are summarized. It has been suggested that the 

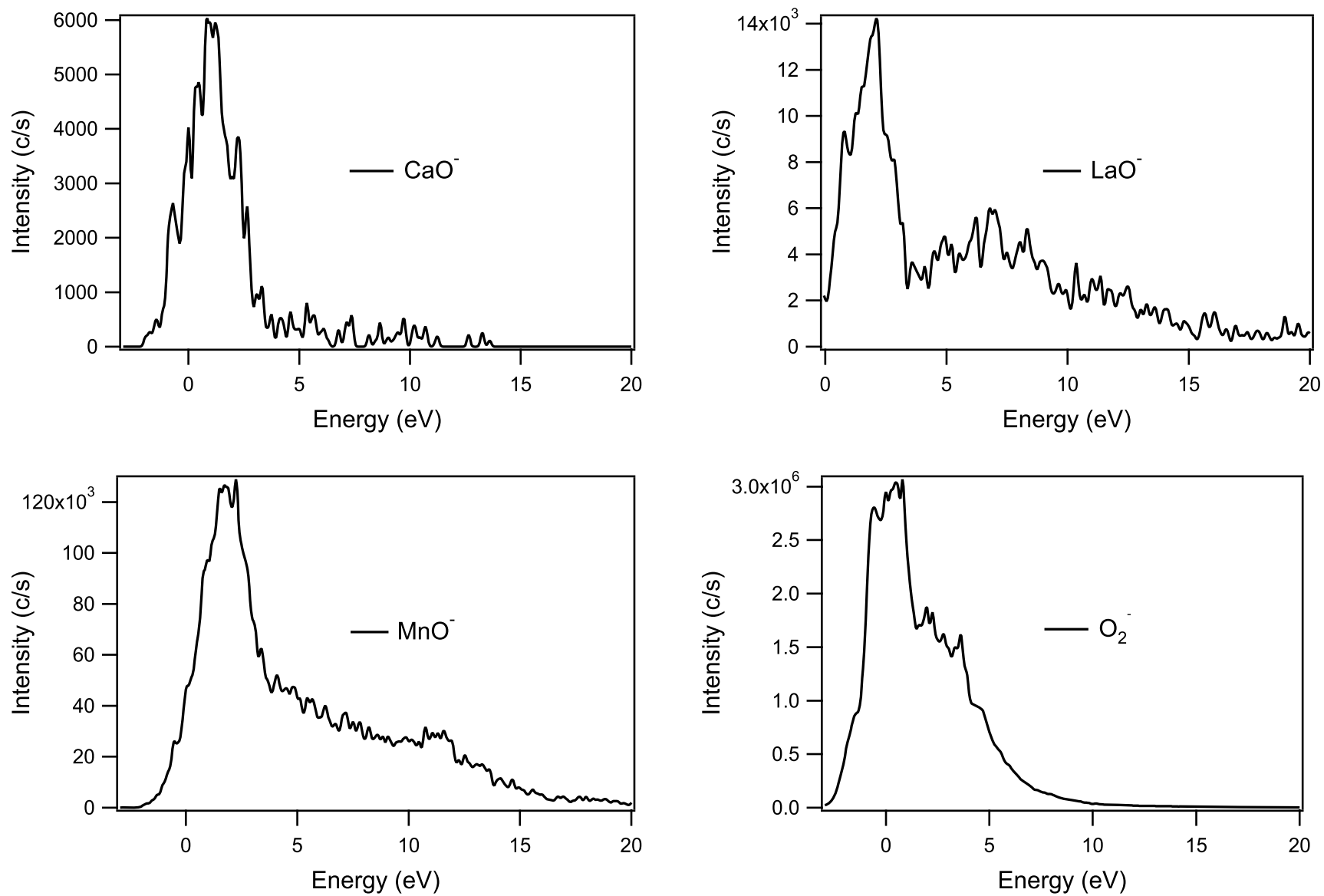

Fig. 6 Measured kinetic-energy distributions of the negatively charged species (at $266 \mathrm{~nm}$ irradiation) created by collisions between the plasma plume and the $\mathrm{N}_{2} \mathrm{O}$ gas pulse

negative species originate from the interactions of electrons with neutral species near the surface region [10]. The negative species are almost not detected in vacuum, and they are most probably formed by collisions with the $\mathrm{O}^{-}$species, e.g. $\mathrm{Mn}+\mathrm{O}^{-} \rightarrow \mathrm{MnO}^{-}$. A large amount of $\mathrm{O}^{-}$and $\mathrm{O}_{2}^{-}$is detected when the gas pulse is applied.

The negatively charged particles are among the slower ions in the plume, even slower than the neutral species. This may be related to the formation mechanisms in the plume, or electrostatic forces within the plume or from the target. The role of negative ions in the process of thin films growth is not clear at the moment, but PRCLA, where more negative ions are produced, has yielded better results in terms of oxygen content for oxide materials.

The maximum energy distribution of the plume species were derived from measured kinetic energy spectra in vacuum and in the presence of $\mathrm{N}_{2} \mathrm{O}$ gas pulse. The data are summarized in Table 3 and the main observations are as follows.

(a) In vacuum, the ionic species are slower than the neutral species. The kinetic energy of the ionic species varies between 4 and $5 \mathrm{eV}$ (with the exception of $\mathrm{O}^{+}$with main kinetic energy at $16 \mathrm{eV}$ ), while the neutral species have kinetic energies between 1 and $3 \mathrm{eV}$.

(b) In the presence of the reactive gas pulse, the ionic plume species are considerable slowed down: by 1 to $2 \mathrm{eV}$ (oxygen decreases from $16 \mathrm{eV}$ to $3.4 \mathrm{eV}$ ).

(c) The negative species are among the slower species in the plume and are mainly formed in the presence of the gas pulse.

(d) The diatomic (positive, negative) $\mathrm{MnO}$ and $\mathrm{CaO}$ species are favorable formed in the gas phase by reactions with oxygen species generated from the $\mathrm{N}_{2} \mathrm{O}$ gas pulse.

\section{Conclusions}

The plume created by laser ablation of a manganite target was investigated by mass spectrometry and kinetic energy analysis. In vacuum, ejection of metal ions, such as $\mathrm{La}^{+}$, $\mathrm{Ca}^{+}, \mathrm{Mn}^{+}, \mathrm{O}^{+}$, was observed, as well as diatomic $\mathrm{LaO}^{+}$. When a reactive $\mathrm{N}_{2} \mathrm{O}$ gas pulse crosses the plasma plume, a considerable increase in the oxide species is observed, i.e. most of the oxide species $(\mathrm{LaO}, \mathrm{MnO}$, and $\mathrm{CaO})$ are 
then detected. The role of the increased oxide yield for thin films growth is under investigations. The $\mathrm{MO}^{-}$and $\mathrm{O}^{-} / \mathrm{O}_{2}^{-}$ species, which are preferentially formed in the plume during interactions with the $\mathrm{N}_{2} \mathrm{O}$ gas pulse, are among the slowest plume species.

The high amount of $\mathrm{O}^{-} / \mathrm{O}_{2}^{-}$species generated by reactive scattering with the $\mathrm{N}_{2} \mathrm{O}$ gas pulse suggests that they may be an important aspect in the films growth, but also fundamentally in PLD, where also plume species collide with gas molecules.

Acknowledgement Financial support of the Swiss National Science Foundation is gratefully acknowledged.

\section{References}

1. A.A. Caparica, A. Bunker, D.P. Landau, Phys. Rev. B 62, 9458 (2000)
2. C.J.L.L.S. Hsu, T.W. Wu, D. Luca, J. Optoelectr. Adv. Mater. 5, 409 (2003)

3. S. Canulescu, T. Lippert, A. Wokaun, R. Robert, D. Logvinovich, A. Weidenkaff, M. Dobeli, M. Schneider, Prog. Solid State Chem. 35, 241 (2007)

4. P.R. Willmott, J.R. Huber, Rev. Mod. Phys. 72, 315 (2000)

5. P.R. Willmott, Prog. Surf. Sci. 76, 163 (2004)

6. P. Lecoeur, A. Gupta, P.R. Duncombe, G.Q. Gong, G. Xiao, J. Appl. Phys. 80, 513 (1996)

7. S.S. Alimpiev, M.E. Belov, V.V. Mlinsky, S.M. Nikiforov, V.I. Romanjuk, Appl. Phys. A: Mater. Sci. Proc. 58, 67 (1994)

8. S.M. Park, J.Y. Moon, Appl. Phys. A: Mater. Sci. Proc. A 69, S695 (1993)

9. H.-J. Dang, M.-F. Zhou, Q.-Z. Qin, Appl. Surf. Sci. 140, 118 (1999)

10. S.C. Langford, L.C. Jensen, J.T. Dickinson, L.R. Pederson, J. Appl. Phys. 68, 4253 (1990)

11. J.B. Pedley, E.M. Marshall, J. Phys. Chem. Ref. Data 15, 943 (1983) 